\title{
The reaction of hydroxylamine with aspirin
}

\author{
Michelle Medeiros, ${ }^{\text {a Bruno S. Souza, }}{ }^{\text {a Elisa S. Orth, }}$, Tiago A. S. Brandão, \\ Willian Rocha, ${ }^{b}$ Anthony J. Kirby, ${ }^{\mathrm{C} *}$ and Faruk Nome ${ }^{\mathrm{a} *}$ \\ ${ }^{a}$ INCT-Catálise, Departamento de Química, Universidade Federal de Santa Catarina, \\ Florianópolis, SC, 88040-900, Brazil \\ ${ }^{b}$ Departamento de Química, Universidade Federal de Minas Gerais, Belo Horizonte, Minas \\ Gerais, 31270-901, Brazil. ${ }^{C}$ University Chemical Laboratory, Cambridge CB2 1EW, UK \\ E-mail:ajk1@cam.ac.uk,faruk@qmc.ufsc.br
}

\begin{abstract}
We dedicate this paper to Rita $\mathrm{H}$. de Rossi, in recognition of her many distinguished contributions to Physical Organic Chemistry
\end{abstract}

\begin{abstract}
Hydroxylamine reacts with aspirin in aqueous solution at $25{ }^{\circ} \mathrm{C}$ predominantly through oxygen, to give $O$-acetylhydroxylamine as the initial product (Scheme 3 ). The reaction is much faster than the intramolecular general base catalysed hydrolysis of the carboxylate anion, as it is also for the $\mathrm{CO}_{2} \mathrm{H}$ form of aspirin. Both reactions are faster than expected, consistent with moderate activation and/or proton transfer catalysis of hydroxylaminolysis by both $\mathrm{CO}_{2}^{-}$and $\mathrm{CO}_{2} \mathrm{H}$ groups. Calculations support oxygen attack as the preferred reaction, but do not permit a clear choice between mechanisms involving $\mathrm{NH}_{2} \mathrm{OH}$ and ${ }^{+} \mathrm{NH}_{3}-\mathrm{O}^{-}$as the effective nucleophile.
\end{abstract}

Keywords: Ester hydrolysis, hydroxylamine, ammonia oxide, alpha-effect, Jaffé plot

\section{Introduction}

Reactions involving nucleophilic attack by hydroxylamine are of special interest because of its remarkably high reactivity in nucleophilic substitutions at carboxylic acyl and phosphoryl centers: which has been accounted for in terms of a unique ambident $\alpha$-nucleophilicity. A $\alpha$-effect nucleophile is identified by the presence of a lone pair of electrons on the atom adjacent to the nucleophilic center: but hydroxylamine is also an ambident nucleophile - alkylated on nitrogen, but typically acylated and phosphorylated on oxygen. ${ }^{1}$ Thus in reactions with methyl 8dimethylamino-1-naphthyl phosphate, hydroxylamine and its $N$-methylated derivatives show similar high reactivity, but reactions with $O$-methylated derivatives are significantly slower. It is proposed that the reactions of $\mathrm{NH}_{2} \mathrm{OH}$ on oxygen involve pre-equilibrium formation of the zwitterionic tautomer ammonia oxide, ${ }^{+} \mathrm{H}_{3} \mathrm{~N}-\mathrm{O}^{-}$, as the active nucleophile (Scheme 1). ${ }^{2}$ 

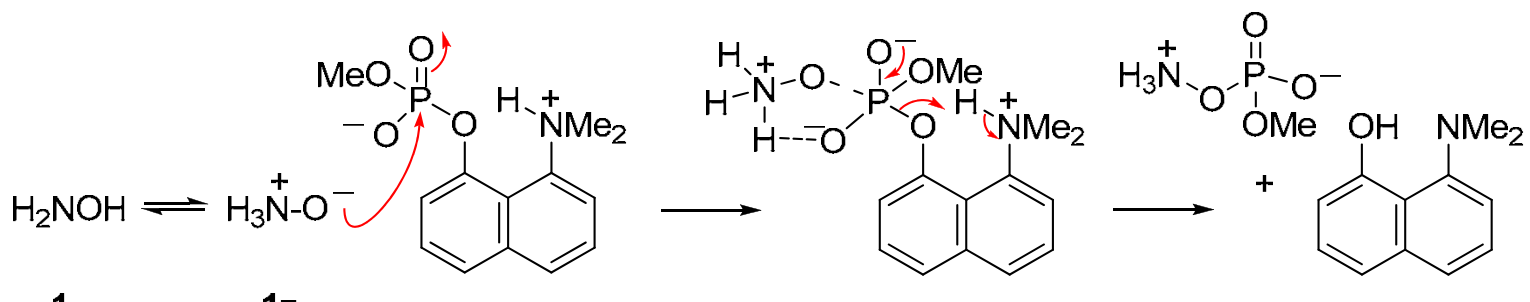

\section{Scheme 1}

The mechanism of nucleophilic attack by hydroxylamine has been discussed extensively over the years. Jencks identified $O$-acylhydroxylamine derivatives as the major initial products in reactions of hydroxylamine with a number of acylating agents, and was the first to attribute the high reactivity to the zwitterionic form of hydroxylamine. ${ }^{3}$ However, alkylation of hydroxylamine occurs on nitrogen rather than on oxygen, and the high acylation reactivity of oxygen could involve intramolecular general acid-base catalysis: which would not be feasible in the concerted linear displacements involved in alkylation. ${ }^{1}$

We have recently shown, using computation and crystallography, that the zwitterionic tautomer $\mathbf{1 z}$ is the preferred form of hydroxylamine in the crystal of its half-hydrochloride $\left(\mathrm{NH}_{2} \mathrm{OH}\right)_{2} \cdot \mathrm{HCl}$. Although $\mathbf{1 z}$ (Scheme 1) is not an $\alpha$-effect nucleophile as usually defined, it is well suited to substitution reactions involving addition-intermediates, because proton transfer from the $\mathrm{H}_{3} \mathrm{~N}^{+}$group to a developing negatively charged center, e.g., the oxygen of a $\mathrm{C}=\mathrm{O}$ or $\mathrm{P}=\mathrm{O}$ group in the substrate, becomes thermodynamically favorable as reaction proceeds (Scheme $1)^{4}$

Proton transfer catalysis is important in many substitution reactions, contributing significant rate enhancements. A classical example is the hydrolysis of the aspirin (acetyl salicylic acid) monoanion, for which water attack is facilitated by intramolecular general base catalysis by the carboxylate group (Scheme 2$)^{5}$
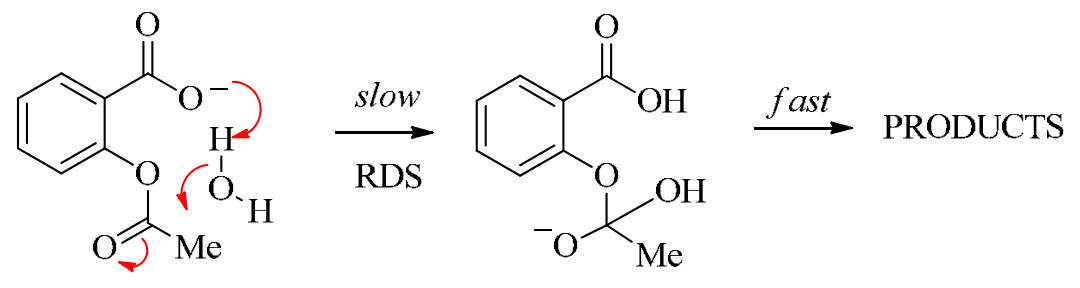

\section{Scheme 2}

We report a study of the reactions of hydroxylamine with substituted aspirins, designed to identify the reactive nucleophile(s) involved - and possible further interesting mechanistic variations. We present new evidence consistent with the dominant nucleophilic contribution of 
the zwitterionic form of hydroxylamine, in competition with a reaction where intramolecular proton transfer is of fundamental importance.

\section{Results and Discussion}

\section{Reaction with hydroxylamine}

Reactions of hydroxylamine with substituted aspirins were investigated at $\mathrm{pH} 6.00$, where only the anionic form of the substrate is present: the $k_{\text {obs }}$ values obtained are plotted in Figure 1 as a function of neutral $\left[\mathrm{NH}_{2} \mathrm{OH}\right]$ concentration. The experimental points in Figure 1 were fitted to Equation 1, where $k_{\mathrm{o}}$ is the rate constant for the spontaneous hydrolysis and $k_{\mathrm{N} 2}$ is the secondorder rate constant for reaction of a substituted aspirin with neutral hydroxylamine. Derived second-order rate constants are given in Table 1 , together with available literature $k_{\mathrm{o}}$ values.

$$
k_{\mathrm{obs}}=k_{0}+k_{\mathrm{N} 2}\left[\mathrm{NH}_{2} \mathrm{OH}\right]
$$

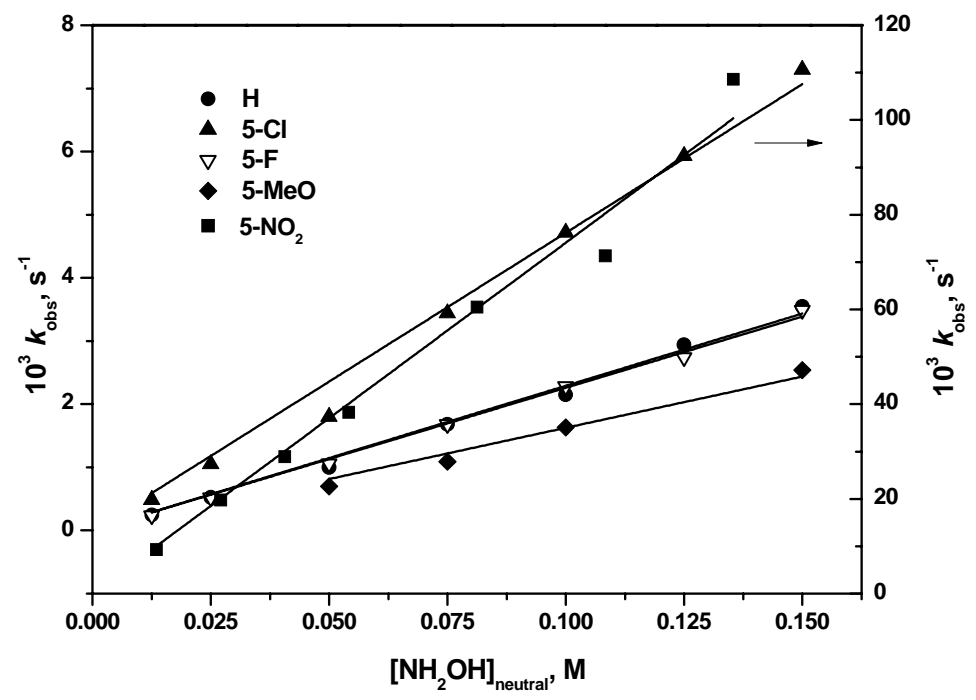

Figure 1. Plot of $k_{\mathrm{obs}}$ as a function of neutral hydroxylamine concentration for reactions with substituted aspirins at $25.0{ }^{\circ} \mathrm{C}, \mathrm{pH}=6.00$ and $\mu=1.0 \mathrm{M}(\mathrm{KCl})$. (Data for the 5- $\mathrm{NO}_{2}$ compound follow the right hand scale.) The concentration of free hydroxylamine was calculated based on $\mathrm{p} K_{\mathrm{a}}=6.0$. Data are given in Table S1 in the Supporting Information.

Table 1.Values of $k_{0}$ and $k_{\mathrm{N} 2}$ for the reactions of hydroxylamine and substituted aspirins, $\mathrm{pH}=$ $6.0,25.0^{\circ} \mathrm{C}$ and $\mu=1.0 \mathrm{M}(\mathrm{KCl})$

\begin{tabular}{ccc}
\hline Aspirin & $10^{6} k_{0}, \mathrm{~s}^{-1 a}$ & $10^{2} k_{\mathrm{N} 2}, \mathrm{M}^{-1} \mathrm{~s}^{-1}$ \\
\hline $5-\mathrm{MeO}$ & 2.20 & 1.62 \\
$\mathrm{H}$ & 2.64 & 2.29 \\
\hline
\end{tabular}


Table 1. Continued

\begin{tabular}{ccc}
\hline Aspirin & $10^{6} k_{0}, \mathrm{~s}^{-1 \text { a }}$ & $10^{2} k_{\mathrm{N} 2}, \mathrm{M}^{-1} \mathrm{~s}^{-1}$ \\
\hline $5-\mathrm{F}$ & 2.64 & 2.26 \\
$5-\mathrm{Cl}$ & 2.86 & 4.71 \\
$5-\mathrm{NO}_{2}$ & 5.57 & 80.2 \\
\hline
\end{tabular}

${ }^{a}$ Data from the literature, estimated for $25^{\circ}$ using $\mathrm{E}_{\mathrm{a}}=18.95 \mathrm{kcal} \mathrm{mol}^{-1}$ as measured for $\mathbf{A A S}^{-5,6}$

The rate of cleavage of aspirin is enhanced up to $10^{4}$-fold in the presence of $0.3 \mathrm{M}$ hydroxylamine, an indication of the magnitude of the apparent $\alpha$-effect: this factor depends on the aspirin substituent, as discussed below.

The $\mathrm{pH}$-dependence of the reaction was also evaluated: reactions of hydroxylamine with substituted aspirins were followed over the $\mathrm{pH}$ range $2-9$, at $25^{\circ} \mathrm{C}$ and ionic strength $\mu=1.0 \mathrm{M}$ $(\mathrm{KCl})$ in buffered solutions containing $0.3 \mathrm{M}$ hydroxylamine. The kinetic results are shown in Figure 2 and the parameters obtained by fitting the data with Equation 2 are given in Table 2. Equation 2 is derived from Scheme 3, which summarises the possible reactions of substituted aspirins and their anions with water and hydroxylamine. In Equation 2, $k_{\mathrm{W} 1}$ and $k_{\mathrm{W} 2}$ correspond, respectively, to the spontaneous hydrolyses of protonated $\left(\chi_{\mathrm{AASH}}\right)$ and anionic $\left(\chi_{\mathrm{AAS}}{ }^{-}\right)$aspirin and $k_{\mathrm{N} 1}$ and $k_{\mathrm{N} 2}$ correspond to reactions of neutral hydroxylamine with nonionic and anionic aspirin, respectively.

As shown in Table 2, the rate constants for the reaction of the anionic form of the aspirin derivatives with hydroxylamine are in all cases at least $10^{4}$ times greater than the rate constants determined for the hydrolysis reaction. ${ }^{6}$ Thus, under the conditions used, a reaction path involving the addition of a water molecule can be ruled out.

$$
k_{\mathrm{obs}}=\left(k_{\mathrm{W} 1}+k_{\mathrm{N} 1}\left[\mathrm{NH}_{2} \mathrm{OH}\right]_{\mathrm{total} \cdot} \cdot \chi_{\mathrm{NH} 2 \mathrm{OH}}\right) \cdot \chi_{\mathrm{AASH}}+\left(k_{\mathrm{W} 2}+k_{\mathrm{N}_{2}}\left[\mathrm{NH}_{2} \mathrm{OH}\right]_{\mathrm{total}} \cdot \chi_{\mathrm{NH}_{2} \mathrm{OH}}\right) \cdot \chi_{\mathrm{AAS}}{ }^{-}
$$

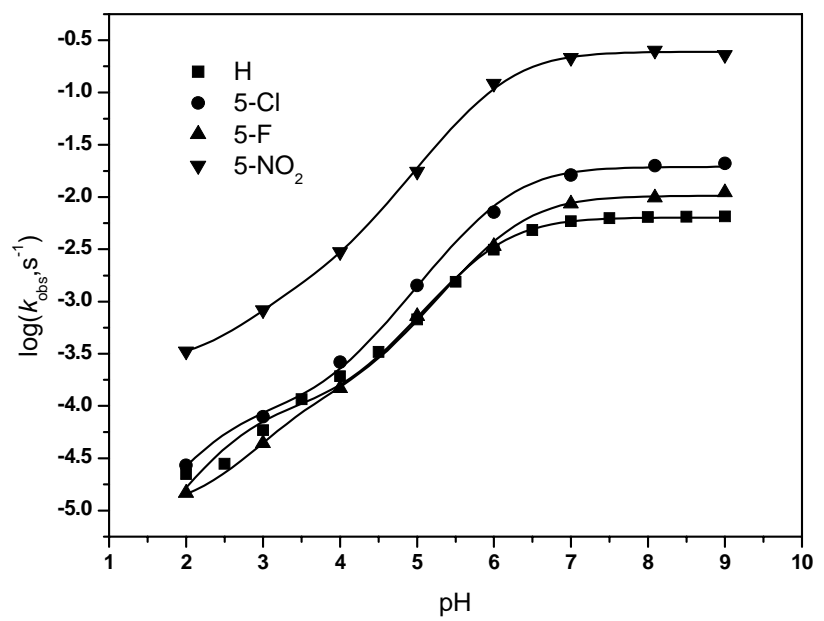


Figure 2. $\mathrm{pH}$ Rate profiles for reactions of substituted aspirins with $0.3 \mathrm{M}$ hydroxylamine at 25.0 ${ }^{\circ} \mathrm{C}$ and $\mu=1.0 \mathrm{M}(\mathrm{KCl})$. The data were fitted to Equation 2 using the kinetic parameters shown in Table 2. Full data are given in Table S2 in the Supporting Information.

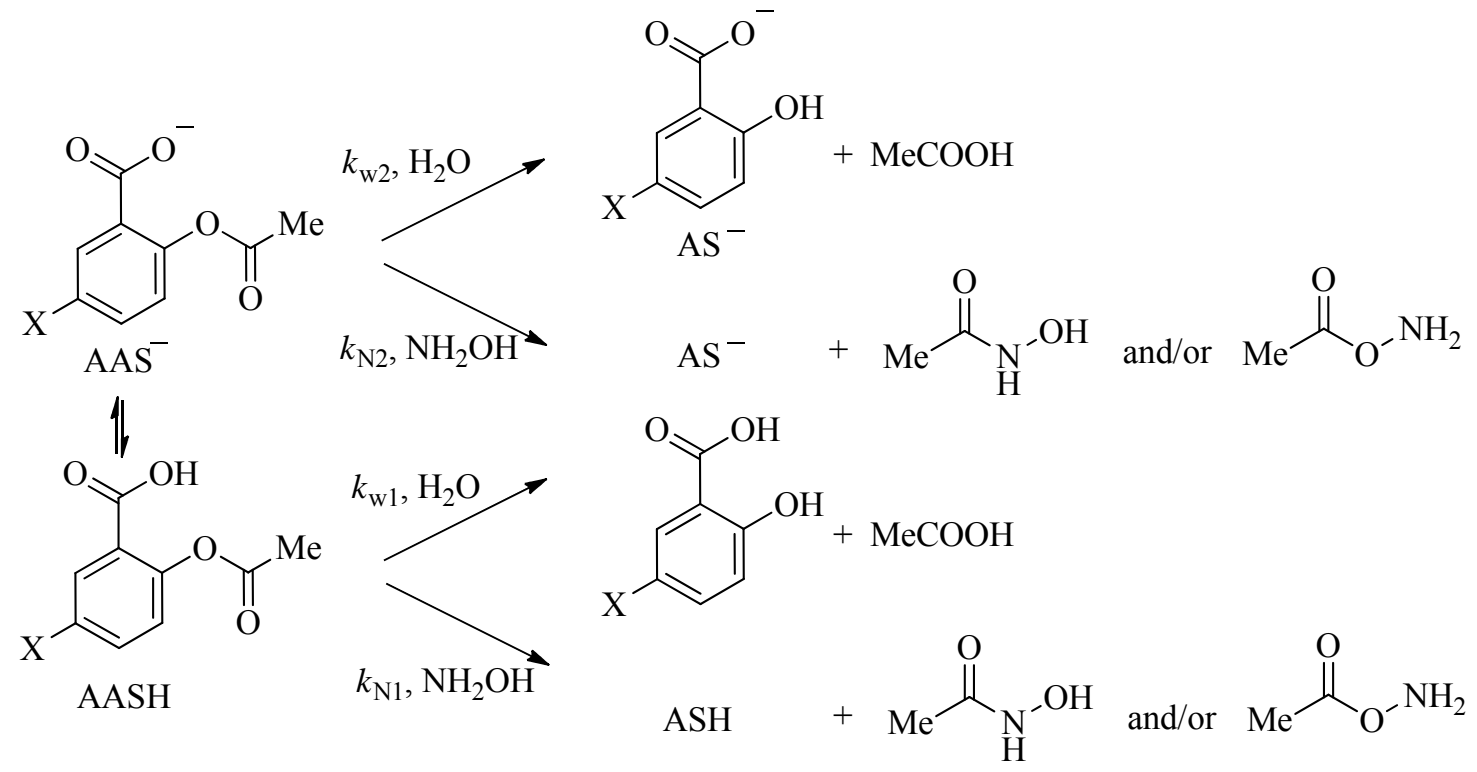

\section{Scheme 3}

The $\mathrm{pH}$-rate profiles for reactions of substituted aspirins with hydroxylamine (Figure 2) show the rate increases with $\mathrm{pH}$ expected from deprotonation of the $\mathrm{NH}_{3}^{+}$group of the nucleophile, reaching a plateau above $\mathrm{pH} 7-8$, where hydroxylamine is fully converted to the free base.

Table 2. Values of $k_{\mathrm{N} 1}$ and $k_{\mathrm{N} 2}$ from fits of $\mathrm{pH}$-rate profiles for reactions of hydroxylamine with substituted aspirins (Scheme 3). Rate constants are within 5\% error

\begin{tabular}{ccccc}
\hline $\mathrm{AAS}, \mathrm{X}=$ & $\mathrm{p} K_{\mathrm{a}}$ & $10^{1} k_{\mathrm{N} 1}, \mathrm{M}^{-1} \mathrm{~s}^{-1}$ & $10^{2} k_{\mathrm{N} 2}, \mathrm{M}^{-1} \mathrm{~s}^{-1}$ & $10^{6} k_{\mathrm{w} 2}, \mathrm{~s}^{-1 a, b}$ \\
\hline $\mathrm{H}$ & $3.38^{\mathrm{c}}$ & 2.65 & 2.18 & 2.64 \\
$5-\mathrm{F}$ & $3.24^{\mathrm{d}}$ & 1.13 & 3.30 & 2.64 \\
$5-\mathrm{Cl}$ & $3.21^{\mathrm{d}}$ & 14.4 & 6.51 & 2.86 \\
$5-\mathrm{NO}_{2}$ & $2.78^{\mathrm{d}}$ & 32.6 & 82.8 & 5.57 \\
\hline
\end{tabular}

${ }^{a}$ Data from Table $1 .{ }^{b}$ Values of $k_{\mathrm{w} 1}$ are at least an order of magnitude smaller. ${ }^{c}$ Data from the literature. ${ }^{7 d}$ Values determined by potentiometric titration at $\mu=0$.

Although the observed rate constants increase with increasing $\mathrm{pH}$ (Figure 2), the reactions of hydroxylamine with the $\mathrm{CO}_{2} \mathrm{H}$ form of the substituted aspirins $\left(k_{\mathrm{N} 1}\right)$ are faster than those $\left(k_{\mathrm{N} 2}\right)$ for reactions with anionic forms (Table 2). As suggested in Scheme 4, the ester carbonyl group of 
neutral aspirin can be activated, and the leaving group stabilized, by intramolecular proton transfer from the carboxylic acid moiety. Similar, stronger interactions in the transition state define the intramoleular general acid catalysis mechanism favored by St. Pierre and Jencks. ${ }^{7}$

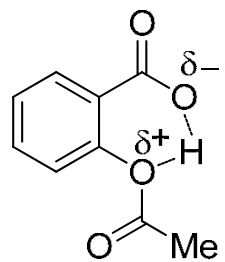

\section{Scheme 4}

The $k_{\mathrm{N} 2}$ values are also at least one order of magnitude larger than values for reactions with comparable phenyl acetates: ${ }^{7}$ unexpectedly, because charge screening and the electronic effect of the $\mathrm{CO}_{2}{ }^{-}$group $\left(\sigma_{\mathrm{m}}=-0.10^{8}\right)$ should disfavor nucleophilic attack (but see St. Pierre and Jencks ${ }^{7}$ ). There appears to be a small but significant electronic (because observed also for $p$ carboxyphenyl acetate ${ }^{7}$ ) effect of $\mathrm{CO}_{2}^{-}$that accelerates attack of hydroxylamine.

Solvent kinetic isotope effect (kie). The reactions were followed at $25.0^{\circ} \mathrm{C}$ in the presence of $0.15 \mathrm{M}\left[\mathrm{NH}_{2} \mathrm{OH}\right]$ in $\mathrm{H}_{2} \mathrm{O}$ and $\mathrm{D}_{2} \mathrm{O}$ at $\mathrm{pH}(\mathrm{D})$ 8.50; i.e. in the plateau region in the $\mathrm{pH}$-rate profile, where both nucleophile and aspirin derivatives are deprotonated. The solvent kinetic isotope effects, $k_{\mathrm{H}_{2} \mathrm{O}} / k_{\mathrm{D}_{2} \mathrm{O}}$, of $1.35-1.75$ (Table 3), are consistent with nucleophilic attack by hydroxylamine, assisted by intramolecular general base catalysis by the carboxylate group. Similar values have been consistently observed for reactions involving nucleophilic attack with proton transfer in the transition state (TS): e.g., for the reaction of hydroxylamine with 8dimethylammonium-naphthyl-1-phosphate monoester, where the solvent deuterium isotope effect is $1.67 .^{9}$

Table 3. Solvent isotope effects $\left(k_{\mathrm{H}_{2} \mathrm{O}} / k_{\mathrm{D}_{2} \mathrm{O}}\right)$ for reactions of hydroxylamine with substituted aspirins at $25.0^{\circ} \mathrm{C},\left[\mathrm{NH}_{2} \mathrm{OH}\right]=0.15 \mathrm{M}, \mathrm{pH}(\mathrm{D})=8.5$ and $\mu=1.0 \mathrm{M}(\mathrm{KCl})$

\begin{tabular}{cc}
\hline Aspirin & $k_{\mathrm{H}_{2} \mathrm{O}} / k_{\mathrm{D}_{2} \mathrm{O}}$ \\
\hline $\mathrm{H}$ & $1.75 \pm 0.09$ \\
$5-\mathrm{F}$ & $1.70 \pm 0.08$ \\
$5-\mathrm{Cl}$ & $1.68+0.12$ \\
$5-\mathrm{NO}_{2}$ & $1.35+0.15$ \\
\hline
\end{tabular}

$\mathrm{N}$-Acetylhydroxylamine concentrations were measured colorimetrically, via complexation with $\mathrm{Fe}(\mathrm{III})$, using a modification of the method of Lipmann and Tuttle. ${ }^{10}$ Yields of $\mathrm{N}$-acetylhydroxylamine were $25 \pm 5 \%$ for all the substituted aspirins, with the exception of the 5 nitro derivative (found: 55\%), for experimental details see Supporting Information. Previous 
studies $^{3,11}$ show that $O$-acetylhydroxylamine isomerises to $N$-acetylhydroxylamine, at a rate which depends on the concentration of hydroxylamine and on the $\mathrm{pH}$ of the medium. Under the conditions used for the quantification of $N$-acetylhydroxylamine, at $\mathrm{pH} 8.50$ and $\left[\mathrm{NH}_{2} \mathrm{OH}\right]=$ $0.05 \mathrm{M}$, the rate constant for the conversion can be estimated to be of the order of $1.2 \times 10^{-4} \mathrm{~s}^{-1}$, giving a half life of approximately $90 \mathrm{~min}$. For the quantification experiments the reactions were followed for $1 \mathrm{~h}$ for H-AAS and 5-F AAS: for $30 \mathrm{~min}$ for 5-Cl AAS, for $80 \mathrm{~min}$ for 5-MeO AAS and for 2 min for $5-\mathrm{NO}_{2}$ AAS. Thus some of the $\mathrm{N}$-acetyl-hydroxylamine measured must come from the isomerisation of $\mathrm{O}$-acylhydroxylamine rather than directly from the reaction with the aspirin. The limited amounts $N$-acetylhydroxylamine formed show that the reactions of aspirins with hydroxylamine occur primarily via the attack of the oxygen atom on the ester carbonyl, forming $O$-acetylhydroxylamine as the major initial product (at least $75 \%$, except for $5-\mathrm{NO}_{2}$ AAS): consistent with the original results of Jencks. ${ }^{3}$ We have carried out a computational investigation to establish which reaction pathway is more favorable: see below.

Jaffé plot. Substituent effects on reactions of hydroxylamine with substituted aspirins were examined by fitting results to Equation 3, which considers the interactions of the OAc group and the carboxylate ion with substituent groups to be independent. Thus a methoxy group should increase the basicity of $\mathrm{CO}_{2}{ }^{-}$, but decrease the electrophilicity of the ester $\mathrm{C}=\mathrm{O}$ group, with opposite effects on the reaction rate. These effects can be assessed separately by using the Jaffé equation (Equation 3), ${ }^{12}$ where $\rho_{\text {acid }}$ is related to the effect on the carboxylate group and $\rho_{\text {phenol }}$ is related to that on the ester group. The Jaffé plot (Figure 3) is based on the data in Table 4.

$$
\log \left(k_{\mathrm{X}} / k_{\mathrm{H}}\right)=\rho_{\text {acid }} \sigma_{\text {meta }}+\rho_{\text {phenol }} \sigma_{\text {para }}
$$

Table 4. Rate constants and parameters used for the Jaffé plot

\begin{tabular}{ccccc}
\hline Aspirin & $10^{2} k_{\mathrm{N} 2}, \mathrm{M}^{-1} \mathrm{~s}^{-1}$ & $\log \left(k_{\mathrm{x}} / k_{\mathrm{H}}\right)$ & $\sigma_{\mathrm{m}}{ }^{*}$ & $\sigma_{\mathrm{p}}{ }^{*}$ \\
\hline $5-\mathrm{MeO}$ & 1.62 & -0.21 & 0.11 & -0.26 \\
$\mathrm{H}$ & 2.29 & - & - & - \\
$5-\mathrm{F}$ & 2.26 & -0.068 & 0.34 & -0.03 \\
$5-\mathrm{Cl}$ & 4.71 & 0.25 & 0.37 & 0.19 \\
$5-\mathrm{NO}_{2}$ & 80.2 & 1.48 & 0.72 & 1.24 \\
\hline
\end{tabular}

$*^{*} \sigma$ values are from Williams. ${ }^{8}$

The derived value of 1.46 for $\rho_{\text {phenol }}$ indicates a TS where the $\mathrm{C}-\mathrm{O}$ bond is approximately $65 \%$ broken (calculated using the effective charge index ${ }^{8}$ ): while the value of -0.81 for $\rho_{\text {acid }}$ indicates a substantial decrease in the negative charge of the carboxylate group, consistent with it acting as an intramolecular general base. The Jaffé parameters are thus consistent with a more or less concerted mechanism, with simultaneous bond formation between the oxygen atom and the carbonyl group and bond breaking between the leaving group and carbonyl center in the TS, 
rather than formation of a discrete tetrahedral addition intermediate, as proposed for aspirin hydrolysis. 5

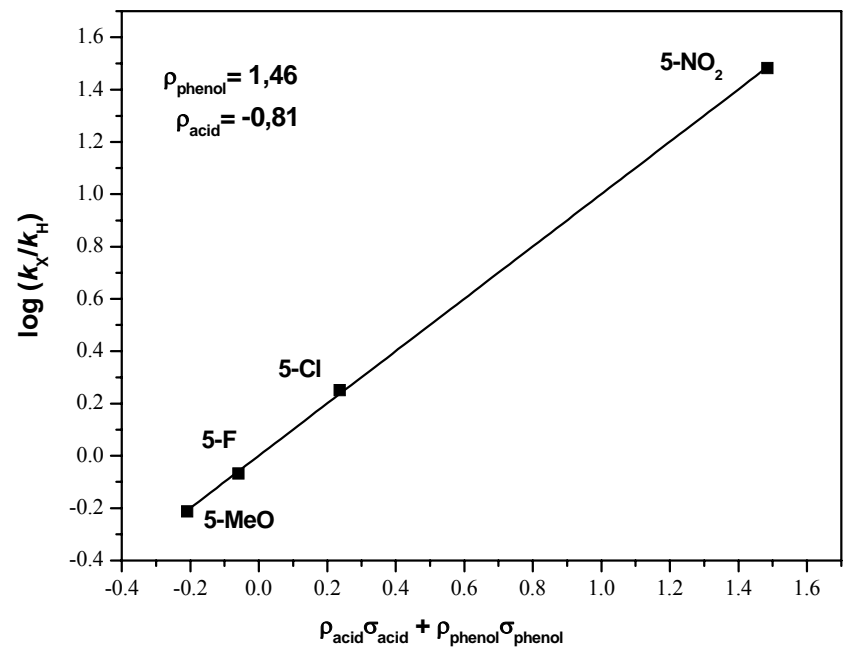

Figure 3. Jaffé plot for reactions of hydroxylamine with substituted aspirins. $\sigma_{\text {acid }}$ and $\sigma_{\text {phenol }}$ are defined as $\sigma_{m}$ or $\sigma_{p}$ depending on the relative positions of group and substituent.

Calculations and proposed mechanisms. Since hydroxylamine is an ambident $\alpha$-nucleophile, equilibrating in solution between $\mathrm{NH}_{2} \mathrm{OH}$ and the zwitterionic ${ }^{+} \mathrm{H}_{3} \mathrm{~N}-\mathrm{O}^{-}$form, we have analyzed three different, kinetically indistinguishable, modes of attack of hydroxylamine on the aspirin anion $\mathbf{A A S}^{-}$(Scheme 3) which could, in principle, account for the KIE observed. In the gas phase, three TS structures were located: TS- $\mathbf{N H}_{2}, \mathbf{T S}-\mathbf{O H}$ and $\mathbf{T S}-\mathbf{O}^{-}$(Figure 4). The first two structures correspond to the attack of neutral $\mathrm{NH}_{2} \mathrm{OH}$ on $\mathbf{A A S}{ }^{-}$by the $\mathrm{NH}_{2}$ and $\mathrm{OH}$ groups, respectively, and the last corresponds to the attack of ${ }^{+} \mathrm{H}_{3} \mathrm{~N}-\mathrm{O}^{-}$. In each of the three TS structures found, the imaginary frequency corresponds to the proton transfer from the nucleophile to the $\mathrm{CO}_{2}^{-}$group concerted with attack by $\mathrm{N}$ (in TS-NH ) or $\mathrm{O} 4$ (in $\mathbf{T S}-\mathbf{O H}$ and $\mathbf{T S}-\mathbf{O}^{-}$) on $\mathrm{C} 2$. Besides the transition states and reactants, no other stable minimum (intermediate) could be found in any of the calculations. Selected structural details of the transition state structures are given in Table 5, along with those of salicylic acid (AS'), acetohydroxamic acid (Nacet), $O$ acetylhydroxylamine (Oacet), hydroxylamine $\left(\mathbf{N H}_{2} \mathbf{O H}\right)$ and the hydroxylamine zwitterion $\left({ }^{+} \mathbf{N H}_{3}-\mathbf{O}^{-}\right)$. Structural details of reactants and products are included in the electronic supporting information.

As shown in Table 5, the extent of proton transfer and bond formation between the nucleophilic and electrophilic centers varies significantly depending on the mode of attack of hydroxylamine. A better understanding of the main structural changes and energy variations along the reaction coordinate can be obtained from IRC calculations in the reverse and forward directions, starting from the three transition states found. These results are shown in Figure 5. 


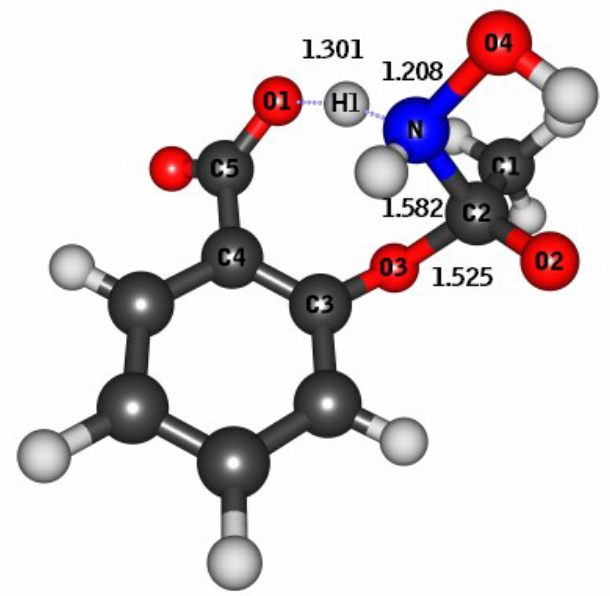

TS-NH

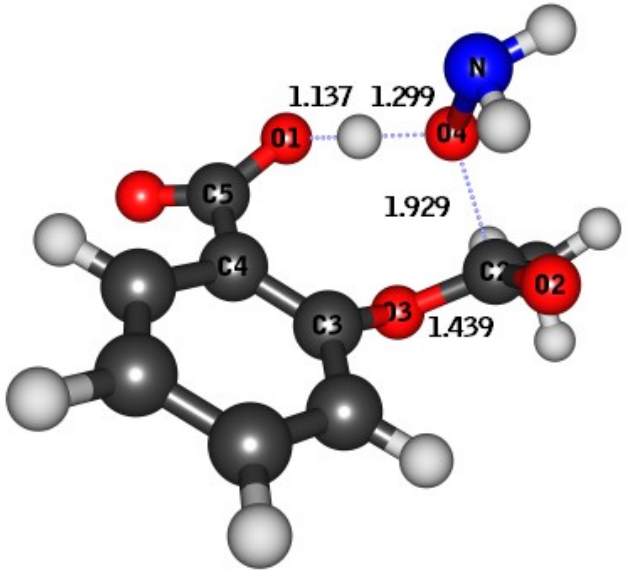

TS-OH

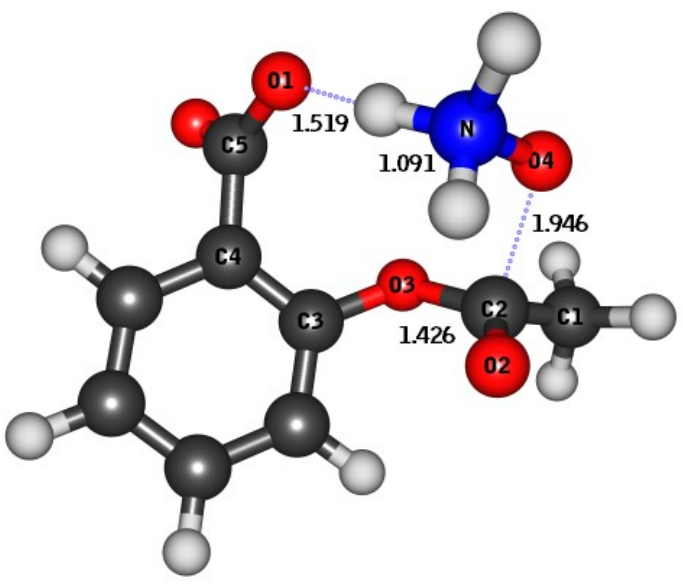

\section{TS-O-}

Figure 4. $\mathrm{B} 3 \mathrm{LYP} / 6-31+\mathrm{g}(\mathrm{d})$ transition state structures for the attack of neutral hydroxylamine through its $\mathrm{NH}_{2}$ and $\mathrm{OH}$ groups (TS- $\mathrm{NH}_{2}$ and TS-OH, respectively) and for the attack of ${ }^{+} \mathrm{H}_{3} \mathrm{~N}-$ $\mathrm{O}^{-}$(TS-O-) on AAS $^{-}$. 
Table 5. Main geometrical parameters of TS-NH $_{2}$, TS-OH, TS-O- ${ }^{-}, \mathbf{A A S}^{-}$, AS ${ }^{-}$, NAcet and OAcet calculated at the B3LYP/6-31+g(d) level. Bond lengths are given in $\AA$ and the dihedral angle is given in degrees

\begin{tabular}{lllllllll}
\hline & $\mathrm{O} 1-\mathrm{H}$ & $\mathrm{N}-\mathrm{H}$ & $\mathrm{O} 4-\mathrm{H}$ & $\mathrm{C} 2-\mathrm{N}$ & $\mathrm{C} 2-\mathrm{O} 4$ & $\mathrm{C} 2-\mathrm{O} 3$ & $\mathrm{C} 2-\mathrm{O} 2$ & $\mathrm{C} 2-\mathrm{O} 3-\mathrm{C} 1-\mathrm{O} 2$ \\
\hline $\mathrm{TS}_{-}-\mathrm{NH}_{2}$ & 1.301 & 1.208 & - & 1.582 & - & 1.525 & 1.278 & 23.520 \\
$\mathrm{TS}-\mathrm{OH}$ & 1.137 & - & 1.299 & - & 1.929 & 1.439 & 1.234 & 15.438 \\
$\mathrm{TS}^{-}{ }^{-}$ & 1.519 & 1.091 & - & - & 1.946 & 1.426 & 1.239 & 14.385 \\
$\mathrm{AAS}^{-}$ & - & - & - & - & - & 1.370 & 1.211 & 1.904 \\
$\mathrm{AS}^{-}$ & 1.037 & - & - & - & - & - & - & - \\
$\mathrm{NAcet}$ & - & - & - & 1.367 & - & - & - & - \\
$\mathrm{OAcet}^{-}$ & - & - & - & - & 1.355 & - & - & - \\
$\mathrm{NH}_{2} \mathrm{OH}$ & - & 1.022 & 0.970 & - & - & - & - & - \\
${ }^{+} \mathrm{NH}_{3} \mathrm{O}^{-}$ & - & 1.036 & - & - & - & - & - & - \\
\hline
\end{tabular}

TS- $\mathbf{N H}_{2}$ shows bond formation between $\mathbf{N H}_{2} \mathbf{O H}$ and $\mathbf{A A S}^{-}$further developed than in $\mathbf{T S}^{-} \mathbf{O}^{-}$ or TS-OH, with a C2-N bond-length of $1.582 \AA$, only $0.215 \AA$ longer than in the product NAcet. As shown in Figs. 4 and 5A, there is also effective intramolecular proton transfer from the developing $\mathrm{H}_{2} \mathrm{~N}^{+}$of $\mathrm{NH}_{2} \mathrm{OH}$ to the neighboring carboxylate oxygen $\mathrm{O}$, with $\mathrm{N}-\mathrm{H} 1$ and $\mathrm{O} 1-\mathrm{H} 1$ distances changing from $1.208 \AA$ and $1.301 \AA$ in $\mathrm{TS}^{-\mathrm{NH}_{2}}$ to $1.298 \AA$ and $1.201 \AA$ at $\mathrm{S}=0.2$, respectively. This proton transfer is concerted with leaving group departure, which is further advanced than in TS-OH, with $\mathrm{C} 2-\mathrm{O} 3=1.525 \AA$ and $\mathrm{C} 2-\mathrm{O} 3-\mathrm{C} 1-\mathrm{O} 2$ equal to $23.52^{\circ}$. As observed for both $\mathbf{T S}^{-} \mathbf{O}^{-}$and $\mathbf{T S}-\mathbf{O H}$, the $\mathrm{C} 2-\mathrm{O} 2(\mathrm{C}=\mathrm{O})$ bond length remains almost unchanged, consistent with a concerted TS, without formation of a tetrahedral intermediate structure.

The transition state structure TS-OH, corresponding to the attack of neutral hydroxylamine on $\mathbf{A A S}^{-}$through its $\mathrm{OH}$ group, shows proton transfer far advanced at $\mathrm{S}=0$, with an O1-H1 bond-length of $1.137 \AA$ and $\mathrm{O} 4-\mathrm{H} 1=1.299 \AA$, corresponding to intramolecular general base catalysis by the substrate carboxylate group. As observed also for the attack of ${ }^{+} \mathrm{H}_{3} \mathrm{~N}-\mathrm{O}^{-}$, the extent of bond formation between $\mathrm{C} 2-\mathrm{O} 4$ is small at $\mathrm{S}=0$, and this bond length decreases before effective proton transfer takes place (Figure $5 \mathrm{~B}$ ); which occurs slightly before $\mathrm{S}=0$. The $\mathrm{C} 2-\mathrm{O} 2$ bond remains almost unchanged in TS-OH (see Table 5), while the carbonyl carbon is considerably out-of-plane, with $\mathrm{C} 2-\mathrm{O} 3-\mathrm{C} 1-\mathrm{O} 2=15.44^{\circ}$. The $\mathrm{C} 2-\mathrm{O} 4$ bond distances are very similar in $\mathbf{T S}-\mathbf{O H}$ and $\mathbf{T S}-\mathbf{O}^{-}$, although in the latter case the original $\mathrm{H} 1$ is transferred to the $\mathrm{CO}_{2}^{-}$moiety only at $\mathrm{S}>2.40 \AA$.

In TS-O ${ }^{-}$there is a very small amount of proton transfer from the ${ }^{+} \mathrm{NH}_{3}$ group to $\mathrm{CO}_{2}{ }^{-}$, the N$\mathrm{H} 1$ bond length increasing from 1.036 in ${ }^{+} \mathrm{NH}_{3}-\mathrm{O}^{-}$to $1.091 \AA$. There is also only a small amount of bond formation between the $\mathrm{C} 2-\mathrm{O} 4$ atoms, which distorts the angle $\mathrm{C} 2-\mathrm{O} 3-\mathrm{C} 1-\mathrm{O} 2$ from $1.90^{\circ}$ in $\mathbf{A A S}^{-}$to $14.38^{\circ}$ in $\mathbf{T S}^{-} \mathbf{O}^{-}$. As shown in Figure $5 \mathrm{C}$, the proton is effectively transferred only at $\mathrm{S}>2.50 \AA$, while $\mathrm{C} 2-\mathrm{O} 4$ bond formation starts before $\mathrm{S}=0$. The $\mathrm{C} 2-\mathrm{O} 3$ bond-length increases with the approach of the nucleophile whereas $\mathrm{C} 2-\mathrm{O} 2$ remains almost constant along the reaction

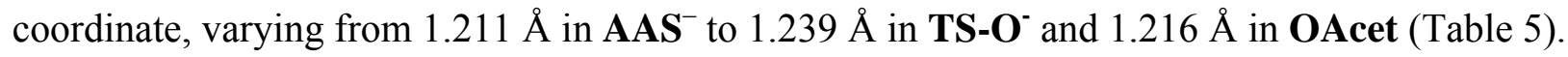



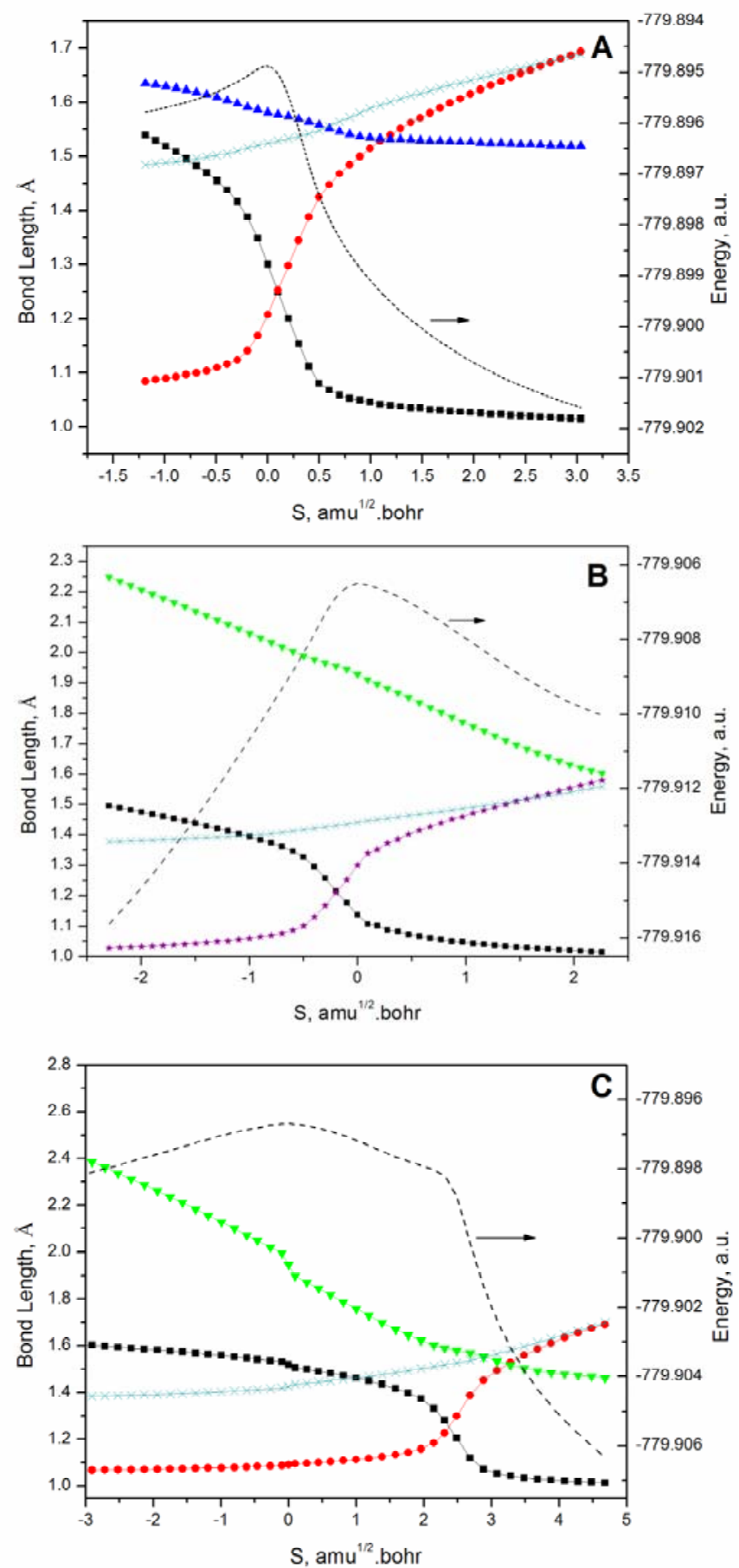

Figure 5. -Intrinsic reaction coordinates (IRC) computed at the B3LYP/6-31+G(d) level for the nucleophilic attack of neutral hydroxylamine through $\mathrm{NH}_{2}(\mathbf{A})$ and $\mathrm{OH}(\mathbf{B})$ and for the attack of

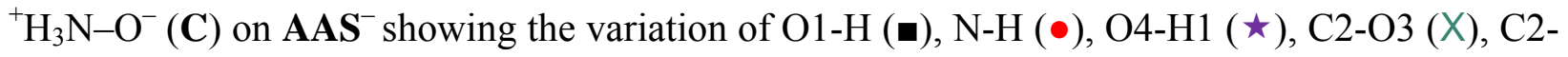
$\mathrm{O} 4(\boldsymbol{\nabla})$ and $\mathrm{N}-\mathrm{C} 2(\boldsymbol{\Delta})$ bonds. The energy variation is given by the dashed line. The $\mathrm{S}=0$ coordinates correspond to TS-NH $\mathbf{2}(\mathbf{A}), \mathbf{T S}-\mathbf{O H}(\mathbf{B})$ and $\mathbf{T S}-\mathbf{O}^{-}(\mathbf{C})$, shown in Figure 4. 
The small amount of bond formation between the nucleophile and the carbonyl carbon in TS$\mathbf{O}^{-}$, with C2-O4 bond equal to $1.946 \AA$ compared to $1.355 \AA$ in OAcet, indicates that TS-O is an early transition state, with neither proton transfer or bond formation well developed.

Computed relative energies, obtained at the MP4(SDQ)/6-31+g(d)//B3LYP/6-31+g(d) level, with solvation effects included, of all species along the reaction coordinate are shown in Figure 6 , where the sum of the reactant energies at infinite separation is taken as the reference point. Starting from $\mathbf{A A S}^{-}$and neutral $\mathbf{N H}_{\mathbf{2}} \mathbf{O H}$ there are high energy barriers corresponding to $\Delta \mathrm{G}^{\ddagger}$ (sol) of 19.64, 20.2 and $24.52 \mathrm{kcal}^{-\mathrm{mol}^{-1}}$ for TS-O', TS-OH and TS-NH $\mathbf{N H}_{2}$, respectively. Clearly, the attack of hydroxylamine through oxygen, in both neutral and the zwitterionic forms, involves

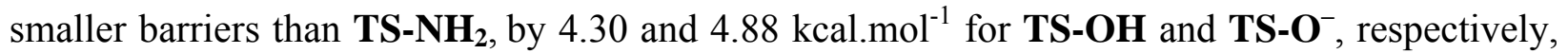
in agreement with the experimental observation of the predominant formation of OAcet. The activation energies calculated for the attack of hydroxylamine through oxygen are very close for the neutral and zwitterionic forms, and in excellent agreement with the experimental value of $19.6 \mathrm{kcal}^{\mathrm{mol}}{ }^{-1}$ (for details see Supporting Information). Results obtained using the B3LYP electronic energies are very similar to those obtained using Equation 4 , giving $\Delta \mathrm{G}^{*}$ (sol) for TS-O' TS-OH and TS- $\mathbf{N H}_{2}$ of 19.26, 19.63 and $26.21 \mathrm{kcal}^{-\mathrm{mol}^{-1}}$. Thus, the theoretical results indicate, correctly, that hydroxylamine attacks $\mathbf{A A S}^{-}$exclusively through oxygen. Since proton transfer takes place with closely similar $\Delta \mathrm{G}^{\ddagger}$ (sol) values in both $\mathbf{T S}-\mathbf{O}^{-}$and $\mathbf{T S}-\mathbf{O H}$, it is not possible to identify the reactive species unambiguously as the neutral or zwitterionic form of hydroxylamine.

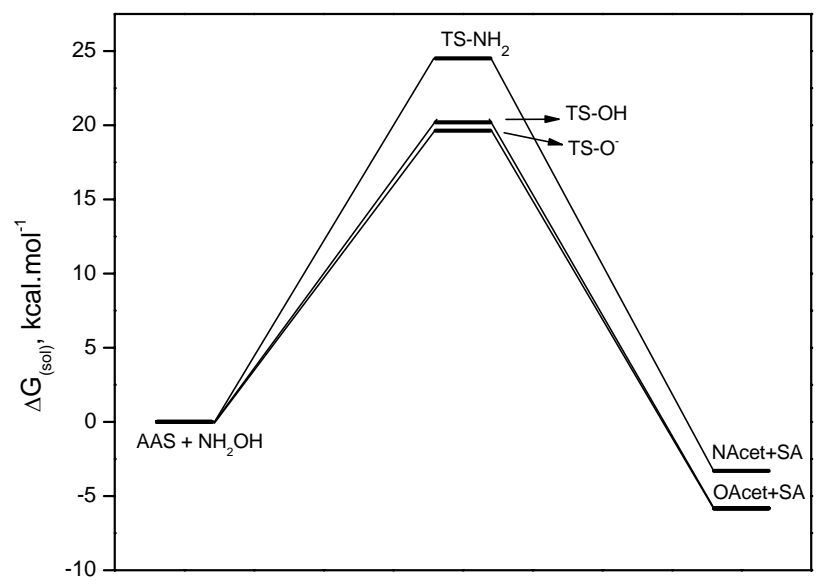

Figure 6. - Free energy variation for the nucleophilic attack of hydroxylamine on AAS obtained at the MP4(SDQ)/6-31+g(d)//B3LYP/6-31+g(d) according to Equation 4. 


\section{Conclusions}

The reaction of hydroxylamine with aspirin in aqueous solution at $25{ }^{\circ} \mathrm{C}$ involves predominant reaction through oxygen, to give $\mathrm{O}$-acetylhydroxylamine (Scheme 3). This isomerizes moderately rapidly to $\mathrm{N}$-acetylhydroxylamine under the conditions. The reaction is overwhelmingly faster than the intramolecular general base catalysed hydrolysis for the carboxylate anion, as it is also for the $\mathrm{CO}_{2} \mathrm{H}$ form of aspirin. Both reactions are also faster than expected for the attack of hydroxylamine on phenyl acetate, consistent with moderate activation and/or proton transfer catalysis of hydroxylaminolysis by both $\mathrm{CO}_{2} \mathrm{H}$ and $\mathrm{CO}_{2}^{-}$groups. Calculations support oxygen attack as the preferred reaction, but do not permit a clear choice between mechanisms involving $\mathrm{NH}_{2} \mathrm{OH}$ and ${ }^{+} \mathrm{NH}_{3}-\mathrm{O}^{-}$as the effective nucleophile.

\section{Experimental Section}

General. Hydrochloride salts of $\mathrm{NH}_{2} \mathrm{OH}$ were obtained from Aldrich. Solutions were prepared immediately before use. All measurements were at $25{ }^{\circ} \mathrm{C}$. Inorganic salts were of analytical grade and were used without further purification. Liquid reagents were purified by distillation.

\section{Synthesis of substituted aspirins}

Substituted aspirins were prepared according to the procedure of Broxton et al., ${ }^{13}$ and identified by ${ }^{1} \mathrm{HNMR}$ and melting point.

\section{Kinetics and product identification}

Reactions were followed spectrophotometrically by monitoring signals of the salicylates at 297$319 \mathrm{~nm}$, on an HP $8453 \mathrm{UV} /$ Vis diode-array spectrophotometer, with a thermostatted cell holder, in aqueous solutions and under first order conditions. The ionic strength was $1.0 \mathrm{M}(\mathrm{KCl})$ and $\mathrm{pH}$ was controlled with $0.01 \mathrm{M} \mathrm{ClCH}_{2} \mathrm{CO}_{2} \mathrm{H}\left(\mathrm{pH}\right.$ 2.00-3.00), $\mathrm{CH}_{3} \mathrm{CO}_{2} \mathrm{H}(\mathrm{pH}$ 4.00-5.00) and TRIS ( $\mathrm{pH} 8.00-9.00$ ) buffers. Solutions at $\mathrm{pH}$ 6.00-7.00 were self-buffered by hydroxylamine. $\mathrm{pH}$ measurements were with a Metrohm model $713 \mathrm{pH}$ meter. For reactions in $\mathrm{D}_{2} \mathrm{O} \mathrm{pD}=\mathrm{pH}_{\text {read }}+$ $0.4{ }^{14}$ Reactions were started by adding $20 \mu \mathrm{L}$ of an acetonitrile stock solution of the substrate to $3 \mathrm{~mL}$ of reaction mixture and substrate concentration in the cuvette was $1.33 \times 10^{-4} \mathrm{M}$, except for 5-nitro-aspirin, where it was $6.67 \times 10^{-5} \mathrm{M}$. All reactions were followed for at least four halflives and observed first-order rate constants, $k_{\mathrm{obs}}$, were calculated from linear plots of $\ln \left(\mathrm{A}_{\infty}-\mathrm{A}_{0}\right)$ against time; correlation coefficients were $>0.999$. Second-order rate constants were calculated from plots of $k_{\text {obs }}$ against [nucleophile]. The salicylates were identified by comparing the final kinetic spectrum with the spectra of standard samples at the same $\mathrm{pH}$. The percentage of attack of hydroxylamine via oxygen or nitrogen atom was evaluated monitoring $\mathrm{N}$ Acetylhydroxylamine as the $\mathrm{Fe}(\mathrm{III})$ complex by a modification of the procedure of Lipmann and Tuttle. $^{10}$ 


\section{Calculations and proposed mechanisms}

Full geometry optimizations and frequency calculations were performed at the gradient-corrected DFT level, ${ }^{15}$ using the hybrid functional formed by the three parameter fit of the exchangecorrelation potential B3, suggested by Becke, ${ }^{16}$ in conjunction with the correlation functional suggested by Lee et al. ${ }^{17}$

All atoms were treated with the all-electron split valence $6-31+G(d)$ basis set, ${ }^{18,19}$ which includes a set of five polarization functions on the $\mathrm{C}, \mathrm{N}$ and $\mathrm{O}$ atoms, with exponential coefficients $\alpha=$ 0.8 , respectively, and also diffuse functions ${ }^{20}$ on these elements. The stationary points located on the gas phase potential energy surface were characterized by calculating the Hessian matrices at the B3LYP level, where the minimum energy structures have no imaginary frequency and the transition-state structures have one imaginary frequency. The transition state structures obtained on the potential energy surface for nucleophilic attack of hydroxylamine towards $\mathbf{A A S}^{-}$were located using the quadratic synchronous approach of Schlegel and co-workers, ${ }^{20}$ starting with a low level computed Hessian matrix for a suitable guess transition state structure. To obtain deeper insight into the reaction mechanism, we calculated the intrinsic reaction coordinate $(\text { IRC })^{21}$ using the Gonzalez-Schlegel second-order path, ${ }^{22,23}$ starting from the optimized transition-state structures, with a step length of 0.100 (a.m.u. $)^{1 / 2}$.Bohr. Aiming to obtain better energetic results, single-point energy calculations on the B3LYP optimized geometries were performed at the fourth order Møller-Plesset perturbation theory with single, double, and quadruple excitations, MP4(SDQ), using the same basis set. Solvent effects $\left(\mathrm{G}_{\text {solvation }}\right)$ were included by means of the polarizable continuum Model $(\mathrm{PCM})^{24}$ in single point calculations, with the molecular cavity computed, explicitly including hydrogen, using the UFF radius. ${ }^{25}$ Thermal corrections to Gibbs free energy $\left(\mathrm{G}_{\text {therm }}\right)$, were estimated at $\mathrm{T}=298.15 \mathrm{~K}$ and $\mathrm{p}=1 \mathrm{~atm}$ using the rigid rotator-harmonic oscillator approximation ${ }^{26}$ at the B3LYP/6-31+G(d) level in vacuum. The Gibbs free energies of all species in solution were obtained using Equation 4, where $\mathrm{G}_{\text {solvation }}$ and $\mathrm{G}_{\text {therm }}$ were obtained at the B3LYP/6-31+g(d) level and are defined above; $\mathrm{E}_{\mathrm{MP} 4}$ is the electronic energy computed in single point calculations at the MP4(SDQ) $/ 6-31+\mathrm{g}(\mathrm{d})$ level.

$$
\mathrm{G}_{(\mathrm{sol})}=\mathrm{E}_{\mathrm{MP} 4}+\mathrm{G}_{\text {solvation }}+\mathrm{G}_{\text {therm }}
$$

All calculations reported here were performed using the Gaussian03 program. $^{27}$

\section{Acknowledgements}

We are grateful to INCT-Catálise, CNPq, Capes, PRONEX and FAPESC for support of this work. 


\section{References}

1. Jencks, W. P. Catalysis in Chemistry and Enzymology; Dover Publications, Inc.: New York, 1969.

2. Kirby, A. J.; Lima, M. F.; da Silva, D.; Roussev, C. D.; Nome, F. J. Am. Chem. Soc. 2006, 128, 16944.

3. Jencks, W. P. J. Am. Chem. Soc. 1958, 80, 4581.

4. Kirby, A. J.; Davies, J. E.; Brandao, T. A. S.; da Silva, P. F.; Rocha, W. R.; Nome, F. J. Am. Chem. Soc. 2006, 128, 12374.

5. Fersht, A. R.; Kirby, A. J. J. Am. Chem. Soc. 1967, 89, 4857.

6. Fersht, A. R.; Kirby, A. J. J. Am. Chem. Soc. 1967, 89, 4853.

7. St. Pierre, T.; Jencks, W. P. J. Am. Chem. Soc. 1968, 90, 3817.

8. Williams, A. Free Energy Relationships; Royal Society of Chemistry: Cambridge, 2003.

9. Kirby, A. J.; Dutta-Roy, N.; da Silva, D.; Goodman, J. M.; Lima, M. F.; Roussev, C. D.; Nome, F. J. Am. Chem. Soc. 2005, 127, 7033.

10. Lipmann, F.; Tuttle, L. C. J. Biol. Chem. 1945, 159, 21.

11. Jencks, W. P. J. Am. Chem. Soc. 1958, 80, 4585.

12. Jaffe, H. H. Chem. Rev. 1953, 53, 191.

13. Broxton, T. J.; Christie, J. R.; Sango, X. J. Org. Chem. 1987, 52, 4814.

14. Fife, T. H.; Bruice, T. C. J. Phys. Chem. 1961, 65, 1079.

15. Parr, R. G.; Yang, W. J. Chem. Phys. 1989, 98, 5648.

16. Becke, A. D. J. Chem. Phys. 1993, 98, 5648.

17. Lee, C.; Yang, W.; Parr, R. G. Phys. Rev. B 1988, 37, 785.

18. Fukui, K. Accts. Chem. Res. 1981, 14, 363.

19. Peng, C.; Schlegel, H. B. Israel J. Chem. 1993, 33, 449.

20. Clark, T.; Chandrasekhar, J.; Spitznagel, G. W.; Schleyer, P. V. R. J. J. Comp. Chem. 1983, 4, 294.

21. Fukui, K. Accts. Chem. Res. 1981, 14, 363.

22. Gonzalez, C.; Schlegel, H. B. J. Chem. Phys. 1989, 90, 2154. 1989, 90, 2154.

23. Gonzalez, C.; Schlegel, H. B. J. Phys. Chem. 1990, 94, 5523.

24. Cossi, M.; Barone, V.; Cammi, R.; Tomasi. J. Chem. Phys. Lett. 1996, 255, 327.

25. Rappe, A. K.; Casewit, C. J.; Colwell, K. S.; Goddard, W. A.; Skiff, W. M. J. Am. Chem. Soc. 1992, 114, 10024.

26. McQuarrie, D. A. Statistical Mechanics; University Science Book: Sausalito CA, 2000.

27. Frisch, G. W. T., H. B. Schlegel, G. E. Scuseria, M. A. Robb, J. R. Cheeseman, J. A. Montgomery, Jr., T. Vreven, K. N. Kudin, J. C. Burant, J. M. Millam, S. S. Iyengar, J. Tomasi, V. Barone, B. Mennucci, M. Cossi, G. Scalmani, N. Rega, G. A. Petersson, H. Nakatsuji, M. Hada, M. Ehara, K. Toyota, R. Fukuda, J. Hasegawa, M. Ishida, T. Nakajima, Y. Honda, O. Kitao, H. Nakai, M. Klene, X. Li, J. E. Knox, H. P. Hratchian, J. B. Cross, C. Adamo, J. Jaramillo, R. Gomperts, R. E. Stratmann, O. Yazyev, A. J. Austin, R. Cammi, C. 
Pomelli, J. W. Ochterski, P. Y. Ayala, K. Morokuma, G. A. Voth, P. Salvador, J. J. Dannenberg, V. G. Zakrzewski, S. Dapprich, A. D. Daniels, M. C. Strain, O. Farkas, D. K. Malick, A. D. Rabuck, K. Raghavachari, J. B. Foresman, J. V. Ortiz, Q. Cui, A. G. Baboul, S. Clifford, J. Cioslowski, B. B. Stefanov, G. Liu, A. Liashenko, P. Piskorz, I. Komaromi, R. L. Martin, D. J. Fox, T. Keith, M. A. Al-Laham, C. Y. Peng, A. Nanayakkara, M. Challacombe, P. M. W. Gill, B. Johnson, W. Chen, M. W. Wong, C. Gonzalez, and J. A. Pople.; Revision D.01 ed.; Gaussian Inc.: Wallingford CT, 2004. 